УДК $595.74(470.324+470.325)$

DOI $10.18413 / 2658-3453-2020-2-24-33$

\title{
ФАУНИСТИЧЕСКИЙ АНАЛИЗ СЕТЧАТОКРЫЛЫХ НАСЕКОМЫХ (INSECTA: NEUROPTERA) ВОРОНЕЖСКОЙ ОБЛАСТИ
}

\section{FAUNISTIC ANALYSIS OF NEUROPTERA OF THE VORONEZH OBLAST}

\author{
Н.Ю. Пантелеева, В.В. Новоселов \\ N.Yu. Panteleeva, V.V. Novoselov \\ Воронежский государственный университет, \\ Россия, 394018, г. Воронеж, Университетская площадь, 1 \\ Voronezh State University, \\ 1 University Sq, Voronezh, 394018, Russia \\ E-mail: nupanteleeva@mail.ru
}

\begin{abstract}
Аннотация
В статье приводятся данные о видовом составе, фаунистических и экологических особенностях сетчатокрылых насекомых Воронежской области. Для региона исследований установлено обитание 27 видов сетчатокрылых из 5 семейств. Наиболее многочисленно по видовому составу и численности семейство Chrysopidae. Выявлен доминантный комплекс, включивший 6 видов из 3 семейств. Результаты биотопического анализа показали, что наиболее богатыми по видовому составу являются лесные и опушечные биотопы. Исследованы фенологические особенности сетчатокрылых в условиях Воронежской области - выделены всесезонная (2 вида), весенняя (1 вид), раннелетняя (5 видов) и летняя (15 видов) фенологические группы.
\end{abstract}

\section{Annotation}

The article presents data on the species composition, faunistic and environmental features of Neuroptera of the Voronezh oblast. In the study region, 27 species of Neuroptera of 5 families were noticed. The most numerous in terms of species composition and abundance is the Chrysopidae family. Dominant species: Chrysopa formosa, Chrysoperla carnea and Chrysopa perla; numerous species: Micromus paganus, Chrysopa phyllochroma and Myrmeleon formicarius. The results of biotopic analysis showed that the richest in species composition are forests (17 species from 3 families) and forest edges (10 species from 3 families). The following phenological groups were distinguished: all season (Chrysoperla carnea, Cunctochrysa albolineata), spring (Micromus paganus), early summer (Italochrysa italica, Hemerobius nitidulus, Mantispaperla,Mantispa styrionausa) and summer (15 species).

Ключевые слова: сетчатокрылые насекомые, фауна, экологические особенности, фенологические группы, Воронежская область.

Keywords: Neuroptera, fauna, environmental features, phenological groups, Voronezh oblast.

\section{Введение}

Сетчатокрылые насекомые встречаются в разных природных зонах Евразии. Большинство видов этого отряда насекомых - обитатели тропического и субтропического климатических поясов, но к настоящему времени на территории Европы известно не менее 300 видов. Имаго большинства представителей этого отряда чаще всего встречаются в травянистом ярусе растительности или на кустарниках и нижних ветвях деревьев и наиболее активны в сумерках.

Имаго и личинки большинства видов сетчатокрылых насекомых являются преимущественно активным хищниками, питающимися тлями, червецами, медяницами, другими мелкими сосущими насекомыми, а также личинками мух и клещами, что определяет их высокое практическое значение [Кривохатский, 2011; Определитель насекомых европейской части СССР, 1987].

В настоящее время для европейской фауны Neuroptera в соответствии с последними сводками по сетчатокрылым насекомым [Aspock, 2012] известны 11 семейств 
и 306 видов. Изученность видового состава Neuroptera России до последнего времени, к сожалению, остается неясной. В частности, для территории России в монографиях и статьях В.А. Кривохатского [Кривохатский, 2011; Кривохатский и др., 2014] указано 34 вида муравьиных львов. Сведения по семейству Chrysopidae содержатся в работах ИВ. Кожанчикова [1953], Г.И. Дороховой [1979], Т А. Волкович [2001], А.В. Присного [2003]; Hemerobiidae - А.В. Захаренко [1989]; Sisyridae - А.Е. Силиной и А.А. Прокина [2000] и В.А. Кривохатского с соавторами [2018]. В последние годы активно изучалась фауна сетчатокрылых Республики Мордовия [Макаркин, Ручин, 2015], Пензенской области [Полумордвинов, 2011, 2012; Полумордвинов, Шибаев, 2012], Северо-Западного Кавказа [Щуров, 2013], Кавказа и Средней Азии [Khabaev, Krivokhatsry, 2014].

Для Среднего Подонья литературные данные о Neuroptera есть только для Воронежской и Белгородской областей [Пантелеева, Новоселов, 2015; Присный, 2003; Голуб и др., 2019]. В Белгородской области отмечен 41 вид сетчатокрылых из 6 семейств: Chrysopidae, Coniopterygidae, Hemerobiidae, Mantispidae, Myrmeleontidae, Sisyridae. B «Кадастре беспозвоночных животных Воронежской области» [2005] указано 7 видов из семейств Chrysopidae, Mantispidae, Sisyridae и 2 вида из семейства Myrmeleontidae. В монографии В.А. Кривохатского [2011] указано наличие в Воронежской области 5 видов муравьиных львов, и 1 новый для региона вид приводится в статье В.Б. Голуба с соавторами [2019]. Кроме этого в литературе высказывалось обоснованное предположение о возможном нахождении в Среднем Подонье 59 видов сетчатокрылых, принадлежащих к 6 семействам [Пантелеева, Новоселов, 2015].

Таким образом, на настоящее время для фауны сетчатокрылых Воронежской области имеются разрозненные данные по видовому составу и его количественному анализу. Целью настоящей статьи является фаунистический анализ населения сетчатокрылых насекомых Воронежской области.

\section{Материал и методы исследования}

Специфика сбора имаго сетчатокрылых насекомых и в целом сравнительно низкая численность представителей этого отряда в естественных условиях обитания определяют небольшой объем собранного материала, который представлен в настоящем исследовании 574 экземплярами. Сетчатокрылые насекомые собирались на территории Воронежской области авторами с 2012 г. по настоящее время, дополнительно использовались материалы энтомологической коллекции кафедры экологии и систематики беспозвоночных животных ВГУ (сборы до 2012 г.). Имаго сетчатокрылых собирались с мая по август в условиях полевого стационара Биологического учебно-научного центра «Веневитиново» Воронежского государственного университета (ВГУ) и во время экспедиционных выездов по территории Воронежской области. Отдельные виды были собраны в январе, марте, апреле и сентябре. Сборы имаго проводились с применением нескольких методов: энтомологическое кошение по травянистой и древесной растительности, индивидуальный отлов, светоловушки (ультрафиолетовый и инфракрасный свет) [Голуб и др., 2012].

Характеристика исследованного материала.

Chrysopa abbreviata (Curtis, 1834): г. Воронеж, опытное поле Воронежского государственного аграрного университета (ВГАУ), VI.1959; 26 км С-В г. Воронеж, «Веневитиново», VI.1958, VII.1968, VII.1957, VI.1959, VII.1975, VI.2012, VII.2013, VII.2014, VI.2015, VI.2016 (на свет); окр. пос. Рамонь, поле, VII.1976, VII.2015.

Chrysopa commata (Kis, Ujhelyi, 1965): 26 км С-В г. Воронеж, «Веневитиново», VI.2012, VII.2014, VI.2015, VII.2017.

Chrysopa dubitans (McLachlan, 1887): г. Воронеж, опытное поле ВГАУ, VI.1959; окр. г. Воронеж, VI.2010; 26 км С-В г. Воронеж, «Веневитиново», VII.1972, VII.2011, VII.2013, VII.2014, VII.2016; окр. пос. Рамонь, поле, VI.1978, VII.2015. 
Chrysopa formosa (Brauer, 1850): г. Воронеж, опытное поле ВГАУ, VI.1959; Ботанический сад ВГУ, VII.1958, VII.2015; окр. г. Воронежа, нагорная дубрава, VI.1957, VII.2017; 26 км С-В г. Воронеж, «Веневитиново», VI.1958, VI.1959, VII.2013, VII.2014, VI.2016; пос. Краснопольский, луг, VII.2012; окр. пос. Рамонь, разнотравье, VII.1976.

Chrysopa pallens (Rambur, 1838): г. Воронеж, опытное поле ВГАУ, VI.1959; близ пос. Яблочное, VI.2014.

Chrysopa perla (Linnaeus, 1758): 26 км С-В г. Воронеж, «Веневитиново», VII.1960, VI.1968, VII.1971, VII.1977, VII.1991, VII.1992, VII.2005, VII.2009, VII.2011, VII.2012, VII.2014, VI.2016; между пос. Яблочным и Архангельским, степные склоны, VI.2014.

Chrysopaphyllochroma (Wesmael, 1841): г. Воронеж, опытное поле ВГАУ, VII.1957, VI.1959; 26 км С-В г. Воронеж, «Веневитиново», VI.1958, VII.1958, VI.1959, VII.1959, VII.1977, VII.2009, VI.2016, VII.2017; окр. пос. Рамонь, поле, VII.1976, VII.1976, V.1979.

Chrysopa walkeri (McLachlan, 1893): г. Воронеж, опытное поле ВГАУ, VI.1959; 26 км С-В г. Воронеж, «Веневитиново», VII.1973, VII.2013, VII.2016.

Chrysoperla carnea (Stephens, 1836): г. Воронеж, квартира (9 этаж), I.2013; 9 км С г. Воронеж, нагорная дубрава, VII.2012; 26 км С-В г. Воронеж, «Веневитиново», VII.1975, VII.1978, VIII.2007, VII.2010, VI.2012, VII.2013, VII.2014, VII.2015, VI.2016, VIII.2017; берег р. Усмань, VII.2007.

Cunctochrysa albolineata (Killington, 1935): 26 км С-В г. Воронеж, Биологический учебно-научный центр ВГУ «Веневитиново», VIII.2010.

Cunctochrysa baetica (Holzel, 1972): 26 км С-В г. Воронеж, Биологический учебнонаучный центр ВГУ «Веневитиново», VII.2010.

Italochrysa italica (Rossi, 1790): 26 км С-В г. Воронеж, «Веневитиново», VI.1959, VI.2016.

Nineta flava (Scopoli, 1763): 26 км С-В г. Воронеж, «Веневитиново», VII.1957, VII.2012, V.2015; окр. пос. Рамонь, поле, V.1978, V.2017.

Nineta vittata (Wesmael, 1841): 26 км С-В г. Воронеж, «Веневитиново», VII.1949, IV.1959, VII.2012, VII.2014.

Pseudomallada prasinus (Burmeister, 1839): окр. пос. Рамонь, VII.1976, VII.2009; 26 км С-В г. Воронеж, «Веневитиново», луг, VII.2010, VII.2015.

Pseudomallada ventralis (Curtis, 1834): 26 км С-В г. Воронеж, «Веневитиново», VII.1974, VII.2012, VI.2016.

Mantispa perla (Pallas, 1772): Лискинский р-н: окр. х. Дивногорье, степные склоны, VII.2014, VII.2017; Новохоперский р-н: окр. с. Рожновка, высыхающее русло р. Пыховка, степные склоны, VII.2009.

Mantispa styriaca (Poda, 1761): Новохоперский р-н: окр. с. Варварино, опушка смешанного леса, VII.2014; Калачский р-н: окр. г. Калач, нагорная дубрава, VI.2016.

Myrmeleon sp. (по всей видимости, кроме M. formicarius, эти сборы включают еще ряд видов, требующих дополнительной диагностики): 26 км С-В г. Воронеж, «Веневитиново», сосновый лес, VII.2011, VII.2012, VII.2014, VIII.2014, VII.2015, VIII.2017; Бобровский р-н: близ с. Лушниковка, опушка соснового леса, VII.2014, VI.2015, VII.2017; Богучарский p-н: близ с. Подколодновка, пески, VIII.2011, VII.2015; близ с. Новый Лиман, VIII.2011, VII.2015; Кантемировский р-н: близ с. Новобелая, пойменный луг р. Белая, VII.2009; Лискинский р-н: близ х. Дивногорье, степные склоны, VI.2012, VII.2014, VII.2018; Павловский р-н: близ с. Белогорье, степные склоны, VII.2013; Россошанский р-н: близ с. Новая Калитва, пойменный луг р. Черная Калитва, VIII.2012.

Deutoleon lineatus (Fabricius, 1798): Кантемировский р-н: близ с. Новобелая, степные склоны вдоль р. Белая, VII.2009; близ с. Волоконовка, степные склоны вдоль р. Белая, VII.2009; Лискинский р-н: близ х. Дивногорье, степные склоны, VI.2012, VIII.2014, VII.2018.

Micromus paganus (Linnaeus, 1767): 26 км С-В г. Воронеж, «Веневитиново», сосновый лес, кошение по кустарникам, VII.2012, VII.2015, VIII.2017. 
Окончание таблицы 1 End of Table 1

\begin{tabular}{|c|c|c|c|c|c|c|}
\hline Виды & $\begin{array}{c}\text { Антропогенные } \\
\text { биотопы }\end{array}$ & Луга & $\begin{array}{c}\text { Опушки } \\
\text { лесов }\end{array}$ & Лeca & $\begin{array}{c}\text { Остепненные } \\
\text { меловые } \\
\text { склоны }\end{array}$ & $\begin{array}{c}\text { Суммарная } \\
\text { относительная } \\
\text { численность } \\
\text { вида }\end{array}$ \\
\hline Cunctochrysa baetica & - & - & - & 1.9 & - & 0.3 \\
\hline Italochrysa italica & - & - & - & 0.9 & - & 0.2 \\
\hline Nineta flava & 16.7 & - & - & 3.9 & - & 1.7 \\
\hline Nineta vittata & - & 25.6 & - & 4.9 & - & 2.3 \\
\hline $\begin{array}{l}\text { Pseudomallada } \\
\text { prasinus }\end{array}$ & 4.8 & - & - & 2.9 & - & 0.8 \\
\hline $\begin{array}{l}\text { Pseudomallada } \\
\text { ventralis }\end{array}$ & - & - & - & 3.9 & - & 0.6 \\
\hline Сем. Myrmeleontidae & & & & & & 8.2 \\
\hline Myrmeleon sp. & - & - & 14.2 & 4.9 & - & 7.6 \\
\hline Deutoleon lineatus & - & - & 1.3 & - & - & 0.6 \\
\hline Сем. Sisyridae & & & & & & 2.0 \\
\hline Sisyra fuscatus & - & - & - & 12.6 & - & 2.0 \\
\hline Сем. Hemerobiidae & & & & & & 13.2 \\
\hline Micromus paganus & - & - & - & - & 40.3 & 9.9 \\
\hline Hemerobius nitidulus & - & 53.8 & 0.3 & - & - & 3.4 \\
\hline Cem. Mantispidae & & & & & & 0.6 \\
\hline Mantispa perla & - & - & - & - & 0.6 & 0.2 \\
\hline Mantispa styriaca & - & - & - & - & 1.9 & 0.4 \\
\hline $\begin{array}{l}\text { Суммарная } \\
\text { относительная } \\
\text { численность } \\
\text { сетчатокрылых по } \\
\text { биотопам }\end{array}$ & 6.5 & 6.0 & 47.3 & 15.8 & 24.4 & 100 \\
\hline
\end{tabular}

На видовом уровне доминантами по численности должны быть признаны Chrysopa formosa (19.2\%), Chrysoperla carnea (15.1\%) и Chrysopa perla (13.4\%). Группу многочисленных видов с относительной численностью от 7.0 до $10.0 \%$ составили: Micromus paganus, Chrysopa phyllochroma и Myrmeleon sp. В группу видов с обычной численностью (1.2-5.5\%) включено девять видов: Chrysopa abbreviata, Chr. pallens, Chr. dubitans, Chr. commata, Hemerobius nitidulus, Nineta vittata, N. flava, Sisyra fuscatus, Cunctochrysa albolineata. Остальные восемь видов отличаются низкой относительной численностью и отнесены в группу малочисленных (см. табл. 1).

За весь период исследований сетчатокрылых насекомых в Воронежской области было обследовано 10 типов биотопов: 1) лесные биотопы: сосновые боры, нагорные дубравы, байрачные леса, а также лесные опушки; 2) открытые биотопы: луга, остепненные меловые склоны (разнотравно-злаковые степи) и прибрежные биотопы; 3) антропогенно измененные биотопы: сельскохозяйственные угодья, лесополосы и пирогенные участки.

Биотопический анализ показывает, что наиболее богатый видовой состав сетчатокрылых в регионе свойственен лесным условиям обитания - 17 видов из 3 семейств при достаточно высокой суммарной относительной численности (15.8\%). Население сетчатокрылых лесных опушек включает 10 видов из 3 семейств, причем оба вида муравьиных львов предпочитают именно эти условия обитания. Именно для этих биотопов характерна самая высокая суммарная относительная численность (47.3\%). Известный состав сетчатокрылых остепненных меловых склонов (разнотравно-злаковые степи) включает 7 видов, принадлежащих к семействам Chrysopidae и Hemerobiidae c суммарной относительной численностью сетчатокрылых в этих биотопах $24.4 \%$. 
Исследование сетчатокрылых луговых биотопов позволило выявить здесь 7 видов из двух семейств, но при низкой суммарной относительной численности $(6.0 \%)$. В условиях антропогенно измененных территорий обитает 10 видов сетчатокрылых из семейства Chrysopidae и в целом суммарная относительная численность изучаемой группы насекомых низка $(6.8 \%)$.

Доминантный комплекс видов лесных и опушечных биотопов включает 5 видов сетчатокрылых, доминирующих по численности или многочисленных в этих условиях (Chrysoperla carnea, Chrysopa formosa, Ch. abbreviata, Ch. phyllochroma, Myrmeleon sp.), a также Sisyrafuscatus, встречающийся в условиях региона только в лесах. В разнотравнозлаковых степях на меловых склонах выявлены два доминирующих по численности вида - Chrysopa perla и Micromus paganus. Луговой доминантный комплекс представлен видами Hemerobius nitidulus, Nineta vittata и Chrysoperla carnea. В антропогенно измененных биотопах шесть из десяти видов сетчатокрылых имеют достаточно высокую относительную численность, причем особого внимания, по нашему мнению, заслуживают два вида, показывающие низкую численность в других условиях обитания: Chrysopa commata и Ch. dubitans (см. табл. 1).

Таким образом, изучение биотопического распределения сетчатокрылых показало, что в условиях Воронежской области они отдают предпочтение лесным и опушечным биотопам. Вполне возможно, что это связано с наибольшей сохранностью мест обитаний Neuroptera в этих ландшафтах.

Особый интерес представляет анализ экологической характеристики известных видов сетчатокрылых насекомых, обитающих в Воронежской области. Представляется возможным выделить 6 групп видов.

1. Эвритопы встречаются во всех или большинстве обследованных биотопов. В эту группу включены Chrysopa abbreviata, Ch. dubitans, Ch. formosa, Ch. pallens, Ch. perla, Ch. phyllochroma, Chrysoperla carnea. По всей видимости, сюда же должны быть отнесены Nineta flava и Pseudomallada prasinus, отмеченные в настоящее время в лесных и антропогенно измененных биотопах.

2. Только в лесных биотопах обитают Cunctochrysa baetica, Italochrysa italica, Pseudomallada ventralis и Sisyrafuscatus.

3. Опушечные условия обитания предпочитают Cunctochrysa albolineata и Myrmeleon sp., относительная численность которых на опушках в три раза выше, чем в лесах, и Deutoleon lineatus, отмеченный только в опушечных биотопах.

4. Степные стенобионты - обитающие в степях на меловых склонах в Воронежской области и отмеченные только в этих условиях. Представлены тремя видами: Micromus paganus, Mantispa perla и M. styriaca. nitidulus.

5. Два вида явно предпочитают луговые биотопы: Nineta vittata и Hemerobius

6. Наконец, два вида сетчатокрылых - Chrysopa commata и Ch. walkeri, в настоящее время явно тяготеют к антропогенно измененным биотопам.

Наши материалы позволяют провести анализ фенологических особенностей сетчатокрылых насекомых в условиях Воронежской области, носящий предварительный характер, т. к. сборы имаго производились в разные годы с мая по сентябрь. К настоящему времени известно, что в мае активны имаго 7 видов, в июне - 16, в июле - 16 и в августе 2 видов (табл. 2).

Суммарная относительная численность сетчатокрылых по месяцам показывает, что этот показатель наиболее высок в июле, в два раза ниже в мае и июне и резко снижается к концу августа.

На основании собранных данных могут быть выделены четыре фенологические группы видов сетчатокрылых: всесезонная, весенняя, раннелетняя и летняя. 
Таблица 2

Table 2

Относительная численность (\%) видов сетчатокрылых насекомых по месяцам

Relative abundance (\%) of winged insect species by month

\begin{tabular}{|c|c|c|c|c|}
\hline \multirow{2}{*}{ Виды } & \multicolumn{4}{|c|}{ Относительная численность } \\
\hline & Май & Июнь & Июль & Август \\
\hline \multicolumn{5}{|l|}{ Ceм. Chrysopidae } \\
\hline Chrysopa abbreviata & - & 15.6 & 1.9 & - \\
\hline Chrysopa commata & - & 2.3 & 2.2 & - \\
\hline Chrysopa dubitans & - & 4.6 & 1.6 & - \\
\hline Chrysopa formosa & 1.3 & 5.8 & 34.8 & - \\
\hline Chrysopa pallens & - & 8.7 & 0.9 & - \\
\hline Chrysopa perla & 46.0 & 3.5 & 3.8 & - \\
\hline Chrysopa phyllochroma & 1.3 & 2.9 & 16.2 & - \\
\hline Chrysopa walkeri & - & 0.6 & 0.3 & - \\
\hline Chrysoperla carnea & 2.7 & 6.4 & 24.8 & 60.0 \\
\hline Cunctochrysa albolineata & - & 5.2 & - & 40.0 \\
\hline Cunctochrysa baetica & - & - & 0.6 & - \\
\hline Italochrysa italica & - & 0.6 & - & - \\
\hline Nineta flava & 4.7 & - & 1.2 & - \\
\hline Nineta vittata & 1.3 & - & 4.0 & - \\
\hline Pseudomallada prasinus & - & - & 1.6 & - \\
\hline Pseudomallada ventralis & - & - & 1.2 & - \\
\hline \multicolumn{5}{|l|}{ Cем. Hemerobiidae } \\
\hline Micromus paganus & 42.7 & - & - & - \\
\hline Hemerobius nitidulus & - & 12.7 & - & - \\
\hline \multicolumn{5}{|l|}{ Cem. Mantispidae } \\
\hline Mantispa perla & - & 0.6 & - & - \\
\hline Mantispa styriaca & - & 1.7 & - & - \\
\hline \multicolumn{5}{|l|}{ Cем. Myrmeleontidae } \\
\hline Myrmeleon sp. & - & 26.5 & 0.9 & - \\
\hline Deutoleon lineatus & - & 2.3 & - & - \\
\hline \multicolumn{5}{|l|}{ Cем. Sisyridae } \\
\hline Sisyra fuscatus & - & - & 4.0 & - \\
\hline $\begin{array}{l}\text { Суммарная относительная численность } \\
\text { сетчатокрылых }\end{array}$ & 23.1 & 26.6 & 49.5 & 0.8 \\
\hline
\end{tabular}

К видам сетчатокрылых, встречающимся в течение всего сезона, по нашим данным может быть отнесен только один - Chrysoperla carnea (см. табл. 2). Вполне возможно, что к этой же группе должен быть отнесен и Cunctochrysa albolineata, сезонная динамика относительной численности которого также показывает нарастание ее к концу сезона.

Весенняя фенологическая группа представлена одним видом - Micromus paganus.

Раннелетняя группа видов включила 5 видов: Italochrysa italica, Hemerobius nitidulus, Mantispa perla, M. styriaca, Deutoleon lineatus.

Пятнадцать видов включены в летнюю группу видов, встречаясь на территории Воронежской области с мая по конец июля (см. табл. 2).

\section{Заключение}

Подводя итог проведенным исследованиям можно говорить, что в настоящее время в Воронежской области достоверно известно обитание 27 видов сетчатокрылых насекомых, принадлежащих к 13 родам и 5 семействам. Наиболее многочисленно по видовому составу и численности семейство Chrysopidae. Доминантный комплекс включает 6 видов из 3 семейств. Биотопический анализ показал, что наиболее богатыми 
по видовому составу являются лесные и опушечные биотопы. Исследования фенологических особенностей сетчатокрылых в условиях Воронежской области позволяют утверждать, что полный видовой состав сетчатокрылых не характерен ни для одного месяца. Наиболее высокие показатели численности приходятся на июль. Выделены всесезонная (2 вида), весенняя (1 вид), раннелетняя (5 видов) и летняя (15 видов) фенологические группы.

\section{Список литературы}

1. Волкович Т.А. 2001. Златоглазки (Neuroptera, Chrysopidae) заповедника «Лес на Ворскле» (Белгородская область): видовой состав и экология. Энтомологическое обозрение, 80 (2): $368-382$.

2. Голуб В.Б., Цуриков М.Н., Прокин А.А. 2012. Коллекция насекомых: сбор, обработка и хранение материала. М., Товарищество научных изданий КМК, 339 с.

3. Голуб В.Б., Голубев А.Е., Томов Р.С. 2019. Первые указания муравьиного льва Myrmeleon bore (Neuroptera, Myrmeleontidae) и осы-сколии Scolia schrenckii (Hymenoptera, Scoliidae) из Воронежской области. $B$ кн.: Современные проблемы зоологии, паразитологии и гидробиологии. Материалы научной конференции с международным участием, посвященной 125 летию со дня рождения профессора И.И. Барабаш-Никифорова (г. Воронеж, 6 декабря 2019 г.). Воронеж, Цифровая типография: 41-44.

4. Дорохова Г.И. 1979. Златоглазки сем. Chrysopidae (Neuroptera) фауны СССР. Энтомологическое обозрение, 58 (1): 105-111.

5. Захаренко А.В. 1989. Новые для фауны СССР виды сетчатокрылых (Neuroptera) семейств Coniopterygidae и Нemerobiidae. Вестник зоологии, 2: 87.

6. Кадастр беспозвоночных животных Воронежской области. 2005. Воронеж, Воронежский государственный университет: 319-320.

7. Кожанчиков И.В. 1953. Сетчатокрылые - Neuroptera. $B$ кн.: Животный мир СССР. Т. 4. М., Изд-во Академии Наук СССР: 424-433.

8. Кривохатский В.А. 2011. Муравьиные львы (Neuroptera: Myrmeleontidae) России. СПб.М., Товарищество научных изданий КМК, 334 с.

9. Кривохатский В.А., Шаповал Н.А., Шаповал А.П. 2014. Муравьиные львы в орнитологических ловушках на Куршской косе: трехвидовое сообщество с новым для науки видом. Зоологический журнал, 93 (1): 605-612.

10. Кривохатский В.А., Волкова Л.Б., Соболев Н.А. 2018. Сизира тёмная - Sisyra fuscata (F.). В кн.: Красная книга Московской области. Московская обл., ПФ «Верховье»: 252.

11. Макаркин В.Н., Ручин А.Б. 2015. Изученность сетчатокрылых и верблюдок республики Мордовия с рекомендациями по включению некоторых видов в основные списки охраняемых таксонов. Труды Мордовского государственного природного заповедника имени П.Г. Смидовича, (15): 133-141.

12. Определитель насекомых европейской части СССР. 1987. T. IV, ч. 6. Большекрылки, верблюдки, сетчатокрылые, скорпионовые мухи, ручейники. Л., Наука: 36-92.

13. Пантелеева Н.Ю., Новоселов В.В. 2015. К изучению сетчатокрылых насекомых (Neuroptera) Среднего Подонья. Вестник Воронежского государственного университета. Сер. Химия. Биология. Фармацчия, (2): 80-83.

14. Полумордвинов O.А. 2011. Megistopus flavicornis (Rossi, 1790) - новый вид для фауны муравьиных львов (Neuroptera, Myrmeleontidae) Пензенской области. Энтомологические и паразитологические исследования в Поволжье, (9): 108-110.

15. Полумордвинов О.А., Шибаев С.В. 2012. Обзор фауны сетчатокрылых (Insecta, Neuroptera) Пензенской области. Известия Пензенского государственного педагогического университета им. В.Г. Белинского. Естественные науки, (29): 256-259.

16. Полумордвинов О.А. 2012. Первая находка Mantispa styriaca (Poda, 1761) (Nturoptera, Mantispidae) на территории Пензенской области. Энтомологические и паразитологические исследования в Поволжье, (10): 108-110.

17. Присный А.В. 2003. Экстразональные группировки в фауне наземных насекомых юга Среднерусской возвышенности. Белгород, Белгородский государственный университет, 296 с. 
18. Силина А.Е., Прокин А.А. 2000. Амфибиотические насекомые урочища «Морозова гора» (Липецкая область) по результатам сборов на свет. $B$ кн.: Эколого-фаунистические исследования в Центральном Черноземье и сопредельных территориях. Липецк: 96-99.

19. Щуров В.И., Макаркин В.Н. 2013. Новые данные о сетчатокрылых (Neuroptera) СевероЗападного Кавказа. Кавказский энтомологический бюллетень, 9 (2): 273-279.

20. Aspock U., Haring E., Aspock H. 2012. The phylogeny of the Neuropterida: long lasting and current controversies and challenges (Insecta: Endopterygota). Arthropod Systematics \& Phylogeny, 70 (2): $119-129$.

21. Khabiev G.N., Krivokhatsky V.A. 2014. Rare species of antlions (Neuroptera Mermeleontidae) new for the fauna of Caucasian and Middle Asian countries. Zoosistematica Rossica, 23 (1): 122-126.

\section{References}

1. Volkovich T.A. 2001. Lacewing (Neuroptera, Chrysopidae) of the Forest on Vorskla Nature Reserve (Belgorod Region): species composition and ecology. Entomological Review, 80 (2): 368-382. (in Russian)

2. Golub VB, Tsurikov MN, Prokin A.A. 2012. Kollektsiya nasekomykh: sbor, obrabotka i khraneniye materiala [Collection of insects: collection, processing and storage of material]. Moscow, KMK Scientific Press Ltd., 339 p.

3. Golub V.B., Golubev A.E., Tomov R.S. 2019. Pervyye ukazaniya murav'inogo l'va Myrmeleon bore (Neuroptera, Myrmeleontidae) i osy-skolii Scolia schrenckii (Hymenoptera, Scoliidae) iz Voronezhskoy oblasti [The first indications of the ant lion Myrmeleon bore (Neuroptera, Myrmeleontidae) and the scolia wasp Scolia schrenckii (Hymenoptera, Scoliidae) from the Voronezh region]. In: Sovremennyye problemy zoologii, parazitologii i gidrobiologii [Modern problems of zoology, parasitology and hydrobiology]. Materials of a scientific conference with international participation dedicated to the 125th birthday of Professor I.I. Barabash-Nikiforov (Voronezh, 6 December 2019). Voronezh, Tsifrovaya tipografiya: 41-44.

4. Dorokhova G.I. 1979. Lacewing fam. Chrysopidae (Neuroptera) fauna of the USSR. Entomological Review, 58 (1): 105-111. (in Russian)

5. Zakharenko A.V. 1989. New for the fauna of the USSR species of the retina (Neuroptera) of the families Coniopterygidae and Hemerobiidae. Vestnik Zoologii, 2: 87. (in Russian)

6. Kadastr bespozvonochnykh zhivotnykh Voronezhskoy oblasti [Cadastre of invertebrate animals of the Voronezh region]. 2005. Voronezh, Voronezh State University: 319-320.

7. Kozhanchikov I.V. 1953. Setchatokrylyye - Neuroptera [Neuroptera]. In: Zhivotnyy mir SSSR [The animal world of the USSR]. T. 4. Moscow, Publishing of Academy of Sciences of the USSR: 424-433.

8. Krivokhatsky V.A. 2011. Murav'inyye l'vy (Neuroptera: Myrmeleontidae) Rossii [Ant lions (Neuroptera: Myrmeleontidae) of Russia]. Saint-Petersburg-Moscow, KMK Scientific Press Ltd., 334 p.

9. Krivokhatsky V.A., Shapoval N.A., Shapoval A.P. 2014. Antlions (Neuroptera, Myrmeleontidae) from ornithological traps on the Coronian Spit: a three-species community containing a new species. Russian Journal of Zoology, 94 (1): 171-178. (in Russian)

10. Krivokhatsky V.A., Volkova L.B., Sobolev N.A. 2018. Sizira tjomnaja - Sisyrafuscata (F.) [Dark sizira - Sisyra fuscata (F.)]. In: Red Book of the Moscow Region. Moscow Region, PF "Verkhovye": 252.

11. Makarkin V.N., Ruchin A.B. 2015. Izuchennost' setchatokrylyh i verbljudok respubliki Mordovija s rekomendacijami po vkljucheniju nekotoryh vidov v osnovnye spiski ohranjaemyh taksonov [The study of the retina and camel of the Republic of Mordovia with recommendations on the inclusion of some species in the main lists of protected taxa]. Proceedings of the Mordovia State Nature Reserve, (15): 133-141.

12. Opredelitel' nasekomyh evropejskoj chasti SSSR [Key to insects of the European part of the USSR]. 1987. Vol. IV, part 6. Big-wings, camels, retina, scorpion flies, caddis flies. Leningrad, Nauka: 36-92.

13. Panteleeva N.Yu., Novoselov V.V. 2015. To the study of the winged insect (Neuroptera) of the Middle Don region. Proceedings of Voronezh State University. Series: Chemistry. Biology. Pharmacy, (2): 80-83. (in Russian) 
14. Polumordvinov O.A. 2011. Megistopus flavicornis (Rossi, 1790) - new species of ant-lions (Neuroptera, Myrmeleontidae) for Penza region fauna. Entomological and Parasitological Investigations in Volga Region, (9): 108-110. (in Russian)

15. Polumordvinov O.A., Shibaev S.V. 2012. Overview of the fauna of the retina (Insecta, Neuroptera) of the Penza region. Izvestija Penzenskogo gosudarstvennogo pedagogicheskogo universiteta im. V.G. Belinskogo. Estestvennye nauki, (29): 256-259. (in Russian)

16. Polumordvinov O.A. 2012. The first find of Mantispa styriaca (Poda, 1761) (Nturoptera, Mantispidae) in the Penza region. Entomological and Parasitological Investigations in Volga Region, (10): 108-110. (in Russian)

17. Prisniy A.V. 2003. Jekstrazonal'nye gruppirovki v faune nazemnyh nasekomyh juga Srednerusskoj vozvyshennosti [Extrazonal groups in the fauna of terrestrial insects in the south of the Central Russian Upland]. Belgorod, Belgorod State University, 296 p.

18. Silina A.E., Prokin A.A. 2000. Amfibioticheskie nasekomye urochishha "Morozova gora" (Lipeckaja oblast') po rezul'tatam sborov na svet [Amphibiotic insects of the tract "Morozova Gora" (Lipetsk region) according to the results of harvesting]. In: Jekologo-faunisticheskie issledovanija $\mathrm{v}$ Central'nom Chernozem'e i sopredel'nyh territorijah [Ecological and faunal studies in the Central Black Earth Region and adjacent territories]. Lipetsk: 96-99.

19. Schurov V.I., Makarkin V.N. 2013. New data on the retina (Neuroptera) of the Northwest Caucasus. Caucasian Entomological Bulletin, 9 (2): 273-279. (in Russian)

20. Aspock U., Haring E., Aspock H. 2012. The phylogeny of the Neuropterida: long lasting and current controversies and challenges (Insecta: Endopterygota). Arthropod Systematics \& Phylogeny, 70 (2): $119-129$.

21. Khabiev G.N., Krivokhatsky V.A. 2014. Rare species of antlions (Neuroptera Mermeleontidae) new for the fauna of Caucasian and Middle Asian countries. Zoosistematica Rossica, 23 (1): $122-126$.

Поступила в редакиию 28.01.2020

\section{Ссылка для цитирования статьи For citation}

Пантелеева Н.Ю., Новоселов В.В. 2020. Фаунистический анализ сетчатокрылых насекомых (insecta: neuroptera) Воронежской области. Полевой журнал биолога, 2 (1): 24-33. DOI: $10.18413 / 2658-3453-2020-2-24-33$

Panteleeva N.Yu., Novoselov V.V. Faunistic Analysis of Neuroptera of the Voronezh Oblast. Field Biologist Journal, 2 (1): 24-33. DOI: 10.18413/2658-3453-2020-2-24-33 